\title{
A CONFIGURAÇÃO DE OBJETOS DE PESQUISA DISCURSIVOS EM MATERIAL MIDIÁTICO
}

\author{
RENATA MARCELLE LARA ${ }^{1}$ \\ Programa de Pós-Graduação em Letras - Universidade Estadual de Maringá \\ Av. Colombo, 5790, Jd. Universitário - 87020-900 - Maringá - PR - Brasil \\ renatamlara@yahoo. com.br
}

Resumo. Pela perspectiva da Análise de Discurso (AD) francesa pecheutiana, este artigo discute a configuração de objetos de pesquisa propriamente discursivos a partir de material de mídia, problematizando possíveis relações entre a Linguística e a Comunicação. Para tanto, descreve uma prática metodológica discursiva realizada em disciplina de metodologia de pesquisa em $A D$ de um programa de pós-graduação em Letras, numa universidade pública paranaense.

Palavras-chave: análise de discurso; metodologia em AD; prática analítica.

\begin{abstract}
By the perspective of French School of Discourse Analysis (AD) based on Pêcheux's perspective, this article discusses the configuration of research objects properly related to discourse, taken from media material, problematizing possible relationship between Linguistics and Communication. To that end, it is described a discourse methodological practice carried out by the discipline of Methodology of Research, in Languages post-graduation program, in a public university of Paranál Brazil.
\end{abstract}

Keywords: discourse analysis; methodology in DA; analytic practice.

\section{Delineando uma entrada}

A temática aqui abordada configura-se como um recorte de uma discussão empreendida sobre a presença da mídia nas pesquisas em Língua e Literatura, que foi tema de uma mesa-redonda realizada no III Encontro Sul Letras, na Universidade Estadual do Centro-Oeste (Unicentro), em Guarapuava (Paraná). É nesse sentido que, para abordar tal recorte temático, parto da noção discursiva de prática ${ }^{2}$ de entremeio, abordada por Orlandi (2012). Tal noção, para mim, tem a ver com o gesto ${ }^{3}$ de interpretação que me constitui pesquisadora. Aponto, nesse caso, como lugar do meu

\footnotetext{
${ }^{1}$ Doutora em Linguística (Unicamp). Professora no Programa de Pós-Graduação em Letras da Universidade Estadual de Maringá (UEM).

${ }^{2}$ Retomo Pêcheux (1997b, p. 218) para esclarecer, tal como o autor, que prática não é tomada como sinônimo de atividade: "a prática não pode ser a prática de um sujeito: não há, para sermos exatos, prática de um sujeito, há apenas os sujeitos de diferentes práticas”.

${ }^{3}$ Gestos como "atos no nível do simbólico", tal como compreende Pêcheux (1997a , p. 78).
} 
dizer, o entremeio que me faz profissional-pesquisadora, na movência e nos deslizamentos de sentidos entre a Linguística e a Comunicação - áreas que integram a minha formação acadêmico-profissional -, pela Análise de Discurso (AD). Entremeio, como esclarece Orlandi (2012, p. 11), que não se reduz a "relações hierarquizadas" ou mesmo "instrumentalizadas", e sim que significa "transversalidade de disciplinas" como empréstimos metafóricos - em alusão que faz a autora a Pêcheux -, no sentido pecheutiano de empréstimos usados como metáforas (transferência de sentidos).

Pondo-me em movimento, pela/na prática de entremeio, objetivo discutir a configuração de objetos de pesquisa propriamente discursivos a partir de material de mídia, do lugar de analista de discurso de vertente materialista, levando em conta relações possíveis de serem estabelecidas entre as áreas da Linguística e da Comunicação. É desse lugar de filiação teórico-metodológica à abordagem de Michel Pêcheux que problematizo as (im)possibilidades de o que (objeto de investigação) e de como (metodologia) pesquisar materiais midiáticos, em Análise de Discurso, nessa e a partir dessa relação. Para visibilizar tais (im)possibilidades, apresento um trajeto metodológico de análise construído com mestrandos e doutorandos do Programa de Pós-Graduação em Letras da Universidade Estadual de Maringá, na disciplina de Metodologia de Pesquisa em Análise de Discurso.

\title{
2. Áreas e objetos em relações
}

Michel de Certeau, em A invenção do cotidiano, afirma:

\begin{abstract}
desde que a cientificidade se atribui lugares próprios e apropriáveis por projetos racionais capazes de colocar zombeteiramente os seus modos de proceder, os seus objetos formais e as condições de sua falsificação, desde que ela se fundou como uma pluralidade de campos limitados e distintos, em suma, desde que não é mais do tipo teológico, a ciência constituiu o todo como o seu resto, e este resto se tornou o que agora denominamos a cultura. (DE CERTEAU, 2013, p. 62)
\end{abstract}

Problematizando certas separações estanques nos domínios científicos, que impõem barreiras separatórias entre áreas do conhecimento - menos para marcar sua especificidade do que para (a)firmar seu poder; menos para dar a compreender os múltiplos sentidos em circulação e mais para (a)firmar sua autoridade naquilo que nega e/ou não compreende como forma outra de conhecimento -, entendo prática de entremeio, no contexto da pesquisa em que se põe em relação a língua e a mídia, como aquilo que me permite transitar entre áreas, a partir de um lugar demarcado, colocando-me em relação com outra área e com outras teorias, sem que estas funcionem como mera somatória ou a grande descoberta.

Isso significa que não se trata apenas de incorporar, do lugar da área Linguística, teorias comunicacionais - assim como não seria o caso de incorporar do lugar da Comunicação teorias linguísticas - como meros acréscimos ou como a descoberta de algo estanque ou menor de como já funciona ou vem sendo trabalhado na área de domínio e/ou de fundação teórica. 
Nos territórios da Linguística, mais especificamente da Análise de Discurso, tenho presenciado um interesse crescente e quase inevitável entre pesquisadores pósgraduandos, mestres e doutores por materiais de mídia e/ou em circulação midiática. Isso tem se intensificado com a profusão tecnológica, com a curiosidade pelo funcionamento da internet, com o crescente acesso ao digital e a intensificação e ampliação das redes sociais.

Exatamente sobre isso, pontuo duas preocupações que materializam o risco dos extremos: a primeira, quanto à busca por explicar textual ou discursivamente o funcionamento da língua na mídia pela apropriação de conteúdos advindos da Comunicação como meros transportes; a segunda, quanto a ignorar as condições de produção específicas de cada materialidade midiática em suas relações sócio-históricas e institucionais no funcionamento linguístico-discursivo.

Chamo a atenção também para um exemplo típico que ainda funciona, embora com menor incidência no meio linguístico. A ideia de que as Teorias da Comunicação se reduzem à Teoria Matemática da Comunicação ou Teoria da Informação, com foco informacional e transmissivo. A confusão entre Teorias do Jornalismo e Teorias da Comunicação. Também, pela ilusão de que as Teorias da Comunicação sejam singulares e não plurais, que elas se originem nos territórios próprios da Comunicação, ausentandose sua constituição na relação com outras áreas.

A questão é que as Teorias da Comunicação, no plural, são um conjunto de teorias advindas, em sua essência, de outras áreas e saberes - da Sociologia, Filosofia, Antropologia, Psicologia, História, Linguística -, que demarcam uma especificidade ao construírem seus objetos próprios de investigação na área comunicacional. É justamente isso que dá a cada área e às pesquisas nas áreas algo diferencial. E é também o que justifica que se faça pesquisa com mídia em áreas que não a da Comunicação ou que se investigue a língua e o discurso na Comunicação ou em outras áreas.

Cada área - seja a Comunicação, a Linguística ou quaisquer outras - tem o seu objeto específico de investigação, assim como as teorias têm os seus, que se põem em relação com a(s) área(s). Trata-se de objetos teóricos. Orientados pelos objetos teóricos das teorias, que estão em relação com o objeto teórico da área, os pesquisadores constroem seus objetos específicos de investigação. Tomo como exemplo a Linguística, cujo objeto teórico é a língua. Como disciplina de entremeio, a Análise de Discurso francesa, fundada por Michel Pêcheux, que faz parte dessa área, tem como objeto teórico o discurso, por ele compreendido como "efeito de sentidos" entre sujeitos (PÊCHEUX, 1997a, p. 82). Discurso que se materializa na língua e na qual e pela qual o analista se debruça, como forma material ${ }^{4}$, em sua autonomia relativa, para compreender $o$ funcionamento discursivo e ideológico.

Desse lugar teórico, o pesquisador constrói seu objeto analítico de investigação, que, em sua construção, já se constitui (ou ao menos deveria se constituir) como um objeto discursivo. Portanto, ele pode selecionar como material de análise, por exemplo, qualquer

\footnotetext{
4 Tal como Orlandi (2012, p. 72), "penso a forma discursiva como forma material, no campo do materialismo histórico, sendo, pois, a forma linguístico-histórica. Nem empírica, nem abstrata. Concebo assim a própria língua no processo histórico-social e coloco o sujeito e o sentido como partes desse processo".
} 
material de mídia, e, com respaldo teórico-metodológico, construir seu objeto discursivo. É por esse objeto discursivo, pensando no e a partir do material de análise, que se desenhará seu corpus analítico. Entenda-se como objeto de investigação o que efetivamente o pesquisador vai investigar e que se encontra dentro do tema, confundindose mesmo com a formulação temática em determinadas situações. Mas não se confunde ou deve ser confundido com material de análise, assim como esse também não é sinônimo de corpus de análise. Se o referencial teórico é a Análise de Discurso pecheutiana, o objeto de investigação tem que ser, por si só, discursivo.

Orlandi tem chamado a atenção para o fato de ser o discurso o objeto teórico da Análise de Discurso. Daí não ser possível falar em novos objetos da Análise de Discurso, mas sim em objetos de investigação, a cada pesquisa, que podem ser múltiplos, sempre com foco no discurso. Tal posição tem se marcado fortemente em suas falas em eventos, como em edições do SEAD - Seminário de Estudos em Análise do Discurso, e em publicações resultantes desse evento, caso do livro $O$ acontecimento do discurso no Brasil (2013), em capítulo intitulado "Análise de discurso, ciência e atualidade". Discussão também presente em seu livro Discurso em análise: sujeito, sentido, ideologia (2012). Nesta publicação, Orlandi (2012, p. 50) alerta: "não confundamos nossos objetos de análise e o nosso objeto teórico que continua sendo sempre o discurso".

Esses cuidados requeridos ao pesquisador sinalizam que pesquisas com o mesmo material de mídia podem ser empreendidas de formas diferentes, não apenas por estarem em áreas distintas e pela possibilidade de se mobilizar teorias diferentes - já que áreas distintas também comungam, em muitos casos, das mesmas teorias -, mas também porque o objeto de investigação se delineia na especificidade da área, associada à teoria nela mobilizada. Quando o material tomado para análise, como no caso exemplificado na Linguística e, propriamente, na Análise de Discurso, é de mídia - seja ela restrita aos meios de comunicação de massa formais, envolvendo impresso, radiofônico, televisivo e digital, seja ampliada a produções informais, mas em circulação midiática -, ele requer que o pesquisador conheça, minimamente, suas condições de produção, para que o objeto a ser investigado possa ser construído como um objeto discursivo.

Conhecer as condições de produção requer que o pesquisador parta do seu território teórico-metodológico e transite de forma entremeada pela área de especificidade investigativa do funcionamento técnico e teórico da mídia tomada em análise. Não se trata de ir buscar um conteúdo para ser transportado para a sua área de pesquisa. Trata-se de, pelos entremeios, conhecer a especificidade da estrutura e do funcionamento do material de mídia, nos seus territórios, e deslocar para seu domínio o que for relevante para delineamento e compreensão do objeto discursivo.

Por causa da forma histórica dos modos de assujeitamento e da existência da discursividade, da materialidade discursiva, ou seja, das condições verbais da produção do objeto, que envolve o processo discursivo instalado historicamente na contemporaneidade, não podemos desconhecer a mundialização, as novas tecnologias da linguagem, a mídia tal como se apresenta hoje [...]. (ORLANDI, 2012, p. 48)

Colocando mais à visibilidade o que busco esboçar, de forma exemplificativa, afirmo que, como pesquisadora na área da Linguística, é possível se valer de estudos 
realizados por pesquisadores da Comunicação, que, por sua vez, já se valeram de pesquisas de outros estudiosos - seja da História Cultural, da Semiótica ou Semiologia, da Sociologia, de estudos de rede digital, entre outros -, para compreender como algo foi pensado na área. Assim, fazer um deslocamento de modo a compreender isso ou algo a partir disso na Análise de Discurso, pela investigação do objeto discursivo construído pelo pesquisador.

O que tem acontecido é que, em determinados casos, nesse passeio teórico, há aqueles que perdem o foco, simplesmente transportando teorias e descobertas da área comunicacional para seus estudos ditos discursivos. O que fica é somente a sensação de novidade, de descoberta, para quem desconhece tais estudos comunicacionais. De fato, não se avança para além daquilo que já está sendo trabalhado em outra área. $\mathrm{O}$ mais problemático é que a análise de discurso (na condição de método de análise) passa a ser reduzida a reproduções de dizeres já em circulação na Comunicação, como se fossem a grande novidade. Estaciona-se na fase de levantamento das condições de produção e a análise, de fato, não se efetiva. Em outros casos, simplesmente se ignora que há condições de produção específicas desses materiais tomados para análise e realiza-se uma análise que, em si, nega os fundamentos teórico-metodológicos que deveriam nortear a investigação.

A orientação que tomo para mim e para meus orientandos, em especial para quem se quer analista de discurso, citando diretamente Orlandi (2012, p. 49), é:

não ver a língua como sistema (o software de um órgão mental) mas como real específico do desdobramento das discursividades; observar as condições de existência dos objetos em uma conjuntura histórica e lembrar que os objetos a saber se constroem em processos discursivos. Pensar as discursividades em suas diferentes materialidades que se desdobram em um espaço contraditório, fazendo-se unidades de análise. Não sermos fixistas e nos dispormos a pensar as formas de circulação desses objetos entre estas zonas (científica, estética, política etc.).

É dessa forma que tenho procurado conduzir as orientações sobre pesquisas com objetos discursivos na Pós-Graduação em Letras, em disciplina específica de Metodologia de Pesquisa em Análise de Discurso.

\section{A construção de um trajeto}

Para ilustrar, cito aqui um trabalho analítico realizado em disciplina de Metodologia de Pesquisa em Análise de Discurso, na Pós-Graduação em Letras (Mestrado e Doutorado) da Universidade Estadual de Maringá, a partir do caso noticiado pela mídia sobre o ataque de um tigre do zoológico do município de Cascavel, no Paraná, a um menino de 11 anos, no dia 30 de julho de 2014, e que teve o braço direito amputado na altura do ombro.

Antes de qualquer coisa, precisamos nos interrogar para qual finalidade empreenderemos uma análise. A construção de um arquivo anterior para seleção de 
material destinado à construção do corpus pode ou não ser requerida, dependendo do caso. Há diferenças caso a análise seja para um artigo, uma comunicação oral, uma iniciação científica, uma dissertação de mestrado ou uma tese de doutorado. Não se trata meramente de quantificação de material, mas de densidade para profundidade analítica, e do que é possível ser feito dentro do tempo disponível regulamentado pelo programa. $\mathrm{O}$ objeto de investigação pode requerer maior quantidade de material se, por exemplo, focalizar os efeitos da circulação em rede quanto ao caso noticiado. Em outras situações, um único material pode render em termos de profundidade analítica porque, para compreendê-lo, é que será necessário percorrer outros materiais.

Quando se trabalha com material noticioso, jornalístico, não se pode desconsiderar o discurso institucional da imprensa, como instituição que discursiviza "sobre", antes mesmo do discurso da empresa jornalística que noticia (em) um determinado contexto sócio-histórico. Requer-se considerar a publicação da notícia, num veículo específico, mas também o local de sua circulação, se na internet, no rádio, na televisão, entre outros. As condições de produção do próprio gênero textual notícia e da notícia como a "matériaprima" do Jornalismo, funcionando no e pelo efeito de novidade e daquilo que se apresenta como sendo o "mais importante", também são requeridos. A identificação, nesse e por esse funcionamento discursivo, dos lugares sociais ${ }^{5}$ dos quais enunciam os sujeitos que falam ou são falados no/do discurso jornalístico. Em meio a isso, também deve-se observar que outras instituições se põem em funcionamento discursivo e como.

Na matéria analisada na disciplina, "Tigre que atacou menino no PR volta para o zoológico", da Agência Estado, assinada por Miguel Portela, e em circulação no site do Yahoo, em 2014, consideramos: a especificidade de uma matéria de agência e da Agência Estado; sua circulação em um site e no site Yahoo; os sujeitos que enunciam de lugares sociais tidos como autoridade do dizer ou autorizados ao dizer, naquele contexto; o próprio lugar de jornalista que dá a ver uma dada realidade. E isso requereu transitar pelos territórios da Comunicação, mais especificamente, do Jornalismo, e naquilo que a Análise de Discurso já teoriza sobre a instituição jornalística, como é o caso de estudos empreendidos por Bethania Mariani (1998; 1999).

Para orientar possibilidades de entrada e observação discursiva do material, organizei a prática metodológica discursiva ${ }^{6}$, que foi desenvolvida com/pelos alunos, em dois momentos. No primeiro, o foco foi para o contato com o conteúdo do material, de modo que se soubesse, ainda em nível jornalístico, o que estava sendo posto em circulação midiática, assim como a amplitude e repercussão do caso noticiado. Esse primeiro momento foi requerido, também, para que o pós-graduando se desse conta de como se é pego ideologicamente, envolvido pela possibilidade de discussão do conteúdo noticiado, quando tendemos a defender ideias e tomar posições com as quais nos identificamos/somos identificados. Associado a isso, ainda estava a tentativa de desmistificação da ideia de que os analistas de discurso desconsideram e/ou desprezam o

\footnotetext{
${ }^{5}$ Sobre esses lugares institucionais, na perspectiva do telejornalismo, considerando a relação lugar social e posição no discurso, $c f$. o capítulo "Lugar, função e posição-sujeito no ritual", parte da tese Versões de um ritual de linguagem telejornalístico (PIMENTEL, 2008).

${ }^{6}$ Emprego "prática metodológica discursiva" no sentido de que não compreendo o trabalho realizado com os alunos como uma atividade ou exercício, mas como uma possibilidade de movimentar-se metaforicamente pelo material analítico, norteados por procedimentos metodológicos sustentados em fundamentos discursivos.
} 
conteúdo, mas se entendesse que para se chegar ao funcionamento discursivo, antes se requer saber que conteúdo é esse que funciona discursivamente.

Intitulei esse momento de “Orientações para Esboço Analítico: Primeira Parte”:

1) Qual é o assunto que possibilitou a seleção do material de análise?

2) Qual a abrangência, em termos de circulação e repercussão, do assunto?

3) Que outros materiais poderiam ser agregados ao material entregue para esboço analítico? De que forma?

4) Que materiais possibilitariam uma análise discursiva a partir do mesmo assunto?

5) Como a seleção do material, em Análise de Discurso, já esboça um percurso inicial discursivo e de que maneira isso afeta a pesquisa?

6) Qual a sua opinião quanto ao fato em si?

7) Essa sua opinião está afetada pelo noticiário midiático? De que forma?

Nessa primeira parte, as perguntas foram enumeradas, sinalizando, justamente, que há uma ordem de leitura a ser seguida. Nível, ainda, do estabilizado, que conduz e rege a organização do pensamento, mas que, justamente nessa e por essa ordem, se buscava desestabilizar essa "certeza", esse lugar de conforto de "ser guiado" que todos nós, de uma forma ou de outra, buscamos, como zona de segurança, principalmente numa situação formal de disciplina acadêmica em que queremos "acertar" ao sermos "avaliados". Ainda figura no meio acadêmico uma "necessidade imensa" por um modelo, uma fórmula, um padrão de análise, de modo que possamos nos guiar. Desejo ainda mais intensificado quando se trata da Análise de Discurso pecheutiana, que não apresenta um "esquema pré-pronto" de como se deve construir a análise, embora os procedimentos estejam inscritos em seus fundamentos teóricos, requerendo que o pesquisador atue como pesquisador, no sentido de saber mobilizar a teoria na construção do seu percurso teóricoanalítico.

Como procedimento inicial, dividi a turma em pequenos grupos de 2 a 4 pessoas. Distribui para cada grupo a matéria jornalística "Tigre que atacou menino no PR volta para o zoológico", da Agência Estado. Solicitei a leitura do material. Em seguida, distribui as perguntas, mas somente com a primeira possível de ser visibilizada, estando as demais perguntas encobertas. Na medida em que uma pergunta era trabalhada, havia fortes marcas de tomada de posição. Alguns se engajavam tão fortemente que parecia uma disputa de poderes para ver quem sabia mais ou tinha argumentos mais consistentes. Aos poucos, as demais perguntas iam, sucessivamente, sendo descobertas e trabalhadas. Ao final, cada grupo apresentou o que havia observado. Com as minhas intervenções, de forma intercalada, eles iam se descobrindo interpelados ideologicamente, $\mathrm{e}$ compreendendo que mesmo não havendo como estar fora da ideologia, há formas e formas de interpelação, tomadas de posição - as mesmas e outras posições -, e possibilidades de, analiticamente, colocar-se funcionamentos discursivos em suspenso, de modo a observá-los discursivamente.

As “Orientações para Esboço Analítico: Segunda Parte”, também constitutivas do que eu chamei de prática metodológica discursiva, foram apresentadas de forma sequencial, embora não enumeradas, sugerindo um percurso possível, mas sinalizando outras direções, possibilidades outras de se construir o próprio percurso analítico- 
discursivo. Tais orientações só foram entregues após o término da realização da primeira parte. Já de início, expliquei que os grupos poderiam se orientar por tais perguntas, mas em qualquer direção, construindo seus próprios percursos. Sinalizei que eram essas as perguntas apresentadas, como poderiam ter sido outras, assim como a disposição de entrada era aquela como poderia ter sido outra. Enfatizei que se tratava de possibilidades de entrada e de tateamento do material, como uma forma de "brincar" com ele, e não de uma fórmula ou modelo de análise.

As "Orientações para Esboço Analítico: Segunda Parte" estavam assim apresentadas:

Pegue o material entregue e esboce, com base nas orientações seguintes, movimentos analíticos iniciais.

- Apresente, por escrito, o material de análise.

- Explique o processo de construção do seu corpus de análise.

- Especifique o gênero textual e suas características.

- Encontre, no material, marcas linguísticas que apontem para alguma repetição significativa, tendo em vista o assunto abordado.

- Tente observar se essas marcas se agregam em algum campo lexical e/ou se podem ser agrupadas de alguma outra forma.

- Tais marcas incomodam de alguma forma? Por quê? Como?

- Identifique os sujeitos que aparecem no material.

- De que lugares sociais os sujeitos enunciam e são referidos?

- Que instituições se fazem presentes na relação com esses lugares?

- Quais são as condições de produção da instituição jornalística?

- Quais são as condições de produção do discurso jornalístico?

- Quais são as condições de produção das instituições e dos discursos institucionais que aparecem no material?

- Retorne às marcas linguísticas e descarte as que deixaram de fazer sentido para seu percurso. Insira outras, se necessário.

- Comece a brincar com as marcas, fazendo paráfrases de conteúdo com elas. De forma sequencial, deixe que apareçam paráfrases discursivas, até que se vislumbre a polissemia, em meio ao funcionamento/processo.

- Observe o que se repete para além do conteúdo.

- Note se essas repetições, pelo sentido, podem ser agrupadas em âmbito discursivo, marcando uma ou mais regularidades.

- Pense sobre o que não é possível de ser aceito de determinados lugares sociais e nas relações institucionais, com base nas regularidades.

- Que sentidos se colocam em funcionamento discursivo?

- Há predominância de determinados sentidos em relação a outros?

- De que posição ou posições discursivas "falam" os sujeitos? Tais posições correspondem ao(s) lugar(es) social(is)? De que forma?

- O esboço que você realizou valida a sua opinião sobre o caso, que foi apresentada no início dessa prática? Como e por quê?

- Que interpretações você pode fazer do seu percurso e a partir dele?

- Alguma coisa, nesse percurso, deixou você inquieto ou em dúvida? O quê? De que forma?

- Qual o seu objeto de análise/investigação? 
- Você tem uma pergunta discursiva para o seu corpus?

- O seu percurso pode ser escrito em forma de artigo científico? Falta alguma coisa? Como e por quê?

O processo de construção de cada percurso foi se dando de forma inquieta e angustiante, tal como se constitui a Análise de Discurso. Depois das discussões internas (intra-grupos), sendo assistidas por mim, e de uma continuidade da prática fora da sala de aula, realizamos, no encontro seguinte, a apresentação geral dos percursos, quando cada grupo expôs seus incômodos, a construção de seus trajetos, suas próprias angústias e descobertas, novas inquietações que se esboçaram.

Tais percursos metodológicos construídos pelos pós-graduandos visibilizaram dois pontos centrais sobre a configuração e investigação de objetos discursivos com material de mídia, que foram, ao final, discutidos com eles: um da ordem do domínio da teoria e do método e outro da ordem do domínio metodológico de sua aplicação, como prática discursiva e, antes, científica. No primeiro caso, a fragilidade analítica resultou, muitas vezes, de um desconhecimento teórico dos fundamentos da teoria e do método, de sua distorção ou, ainda, de um "não saber" relacionar, ainda em nível de compreensão teórica, teoria e método. No segundo caso, adveio do desconhecimento de procedimentos metodológicos discursivos que possibilitam integrar teoria e método analiticamente, no sentido de não se perguntar pelo conteúdo (sem, contudo, desconsiderá-lo), mas pelo processo, pelo funcionamento, requerendo o levantamento das condições de produção relevantes ao material, da observação de pré-construídos e de outros estabilizados das áreas que se põem em jogo. Antes, resultou do desconhecimento de procedimentos metodológicos básicos de pesquisa e análise, norteadores do campo científico. Em parte significativa dos casos envolvendo os grupos que foram organizados para construção de um trajeto analítico como prática metodológica discursiva, em que se visibilizasse um objeto discursivo de investigação, notou-se carência de domínio de noções básicas sobre metodologia de pesquisa científica de modo geral, antes mesmo que em sua especificidade em $\mathrm{AD}$ - o que sinaliza para uma problemática no interior do próprio campo científico quanto ao domínio de práticas metodológicas de investigação.

No segundo semestre de 2015, adaptei a prática metodológica discursiva realizada com os mestrandos e doutorandos para desenvolver, também na disciplina de Metodologia de Pesquisa em Análise de Discurso, com outra turma da Pós-Graduação em Letras, envolvendo o assunto Selfies. Dessa vez, reuni um conjunto de materiais (jornalísticos e não jornalísticos), que circularam em sites, sobre museu de selfies, selfies em museus, entre outros assuntos que se relacionavam a esse. Novamente, a prática trouxe retornos significativos, pelas possibilidades desestabilizadoras da descoberta de si como pesquisador em Análise de Discurso.

\section{Compondo um fecho}

O trajeto teórico e a prática metodológica discursiva descrita neste texto - no sentido de vislumbrarem-se objetos discursivos possíveis de investigação científica na área da Linguística, partindo de materiais de mídia, pela Análise de Discurso, sem que sejam esquecidas as especificidades das áreas postas em relação teórica e analítica - 
sinalizam que a cada movimento de análise, reivindica-se, de forma contínua, a relação teoria-método, já que a Análise de Discurso é, constitutivamente, teoria e método. Nessa composição entremeada intrínseca, "a análise de discurso é, antes de tudo, análise" (ORLANDI, 2012, p. 12). Para que a análise aconteça, requer-se que se delineie um objeto de investigação discursivo, no interior do aporte teórico e metodológico, de modo a se construir uma entrada no material - considerando-se o que lhe é específico -, seja esta ou não previamente norteada por uma pergunta discursiva, pois ela pode surgir em meio ao percurso.

Sem mobilizar o objeto da teoria, que é o discurso, e sem delinear o objeto de pesquisa, dentro da teoria, aportado nela e por ela, assim como em seu método, o trajeto metodológico propriamente discursivo não se estrutura e tampouco se efetiva. Daí que qualquer tentativa de levantamento das condições de produção, dos lugares sociais, entre outros procedimentos requeridos na análise discursiva, não se sustenta se o objeto de investigação não estiver devidamente configurado.

Dessa forma, para saber "o que" e "como" pesquisar, no que se refere à configuração de objetos de pesquisa discursivos a partir de material de mídia, pondo-se em relação a Linguística e a Comunicação, requer-se, antes, que se conheçam essas áreas de seu próprio interior: primeiro, seus objetos teóricos, e, tão logo, seus possíveis objetos de investigação - estes também objetos analíticos em Análise de Discurso ${ }^{7}$. Ao assumir uma posição de entremeio, o pesquisador em Análise de Discurso tem condições de partir de um material midiático e configurar um objeto de investigação propriamente discursivo, assim como delinear seu trajeto metodológico como prática, que é discursiva.

A prática metodológica realizada na pós-graduação, na disciplina de Metodologia de Pesquisa em Análise de Discurso, demonstrou o quanto aprendemos o que é e o que não é análise discursiva no próprio processo de sua realização, em que teoria e método se reivindicam, encontram-se e se efetivam. É no e pelo processo analítico-discursivo que desestabilizamos (nossas) "certezas", assim como as "verdades" das áreas, considerando o que lhes é específico e o que pode ser entremeado discursivamente, ao assumirmos o lugar e a posição de analista.

Para delinear o término dessa discussão cujo foco foi para a configuração de objetos de pesquisa propriamente discursivos partindo de material midiático, ao se por em relação a Linguística e a Comunicação, pela Análise de Discurso pecheutiana, e requerendo do analista uma posição de entremeio, trago uma citação da pesquisadora em

\footnotetext{
${ }^{7}$ Ressalto, novamente, em outras palavras, que enquanto o objeto teórico é o objeto de cada teoria ou mesmo da área - se o tomarmos em sua dimensão mais abrangente -, o objeto de pesquisa, que também pode ser chamado de objeto de investigação, é construído dentro de uma determinada área e da teoria escolhida pelo pesquisador, na relação com o objeto teórico da teoria/área. Portanto, ao nos referirmos à objeto de análise, este está na relação com o objeto de pesquisa, construído para uma dada investigação. Não utilizamos o termo objeto de análise como sinônimo de material de análise, como o faz determinados pesquisadores de Análise de Discurso. Também não consideramos sinônimos os termos conceituais material de análise e corpus de análise. O material é aquele sobre o qual se debruçará o pesquisador para, então, construir, em/por um trabalho analítico-discursivo, o corpus de sua pesquisa, que só se delineia no próprio percurso, em que se põe em relação teoria e método, num jogo contínuo, sem início ou fim previamente demarcado. Diferenciação metodológica que Orlandi (2000) explica pelo emprego dos termos corpus bruto (material de análise) e corpus específico (corpus de análise propriamente dito).
} 
Comunicação, Rose de Melo Rocha, retirada de um capítulo do livro Ecos urbanos: a cidade e suas articulações midiáticas.

Nas cidades-mídia caminha-se do espetáculo para a introjeção dos artifícios. Estetização da cultura. Musealização do urbano. Mas também explosão em cascata de imagens-mundo, multiplicação das miradas, profusão de imaginários, contrabando irrefreável de afetos e sentidos. Nas sociedades contemporâneas, onde muito se vê e pouco se olha, o devaneio como método de olhar convive com a alucinação do próprio real. Imagens-esfinges, fábulas visuais convocam $o$ vidente, capturando-o em um jogo de submersão visual que, por vezes, eclipsa a possibilidade de refletir sobre o vivido. O olhar é interpelado pela permissividade endoscópica que convida ao tudo devassar e ao rápido devastar. Só nos resta pensar o mundo através desse mesmo olhar. Redirecionando os fluxos; transitando indagativamente e de olhos bem abertos pelo olho do furacão. (ROCHA, 2008, p. 92)

Estamos diante de múltiplos funcionamentos e circulações discursivas em uma cidade tecnológica, digital(izada), que se constitui na e pela midiatização. Não podemos ignorar isso, mas também não podemos ser pegos pelo efeito naturalizador que isso causa em nós, como moradores dessa cidade, e em nós como pesquisadores tomados pela contradição da certeza de nossas hipóteses. Daí a importância, como pesquisadores, de nos colocarmos em movimento, no entremeio, que tanto a Linguística pode fazer em relação à Comunicação, para investigar materiais midiáticos, quanto a Comunicação pode fazer em relação à Linguística, e não só no que diz respeito à Análise de Discurso, mas às investigações de modo geral.

\section{Referências bibliográficas}

DE CERTEAU, Michel. A invenção do cotidiano: artes de fazer. 20ª . ed. Trad. Bras. Petrópolis: Vozes, 2013.

MARIANI, Bethania. Discurso e instituição: a imprensa. RUA [Revista do Núcleo de Desenvolvimento da Criatividade da Unicamp, Nudecri], Campinas, n. 5, 47-61, março 1999.

O PCB e a imprensa: os comunistas no imaginário dos jornais (1922-1989). Rio de Janeiro: Revan; Campinas: Editora da Unicamp, 1998.

ORLANDI, E.P. Análise de discurso, ciência e atualidade. Em: INDUSKY, F.; FERREIRA, M.C.L; Mittmann, S. (Orgs.). O acontecimento do discurso no Brasil. Campinas: Mercado de Letras, 2013. p. 17-30.

Análise de discurso: princípios e procedimentos. 2a ed. Campinas: Pontes, 2000.

Discurso em análise: sujeito, sentido, ideologia. Campinas: Pontes, 2012. 
PÊCHEUX, Michel. Análise Automática do Discurso (AAD-69). Parte I: Análise de conteúdo e teoria do discurso. Em: HAK, T.; GADET, F. (Orgs.). Por uma análise automática do discurso: uma introdução à obra de Michel Pêcheux. $3^{a}$. ed. Trad. Bras. Campinas: Editora da Unicamp, 1997a. p. 61-105.

Semântica e discurso: uma crítica à afirmação do óbvio. $3^{\mathrm{a}}$. ed. Trad. Bras. Campinas: Editora da Unicamp, 1997b.

PIMENTEL, Renata Marcelle Lara. Lugar, função e posição-sujeito no ritual. Em: Versões de um ritual de linguagem telejornalístico. Tese. Doutorado em Linguística, Instituto de Estudos da Linguagem, Universidade Estadual de Campinas, Campinas, SP, 2008. p. 49-105.

PORTELA, Miguel. Tigre que atacou menino no PR volta para o zoológico. Agência Estado. Yahoo Notícias. Disponível em: <https://br.noticias.yahoo.com/tigre-atacoumenino-pr-volta-zool-gico-002600554.html>. Acesso em 5 ago. 2014.

ROCHA, Rose de Melo. Cidades palimpsestas, cidades midiáticas: limiaridades e errâncias que produzem significação. Em: PRYSTHON, A.; CUNHA, P. (Orgs.). Ecos urbanos: a cidade e suas articulações midiáticas. Porto Alegre: Sulina, 2008. p. 91-110.

\section{$* * *$}

Artigo recebido em: janeiro de 2016.

Aprovado e revisado em: junho de 2016.

Publicado em: agosto de 2016

\section{Para citar este texto:}

LARA, Renata Marcelle. A configuração de objetos de pesquisa discursivos em material midiático. Entremeios [Revista de Estudos do Discurso], Seção Estudos, Programa de Pós-graduação em Ciências da Linguagem (PPGCL), Universidade do Vale do Sapucaí, Pouso Alegre (MG), vol. 13, p. 3-14, jul. - dez. 2016.

DOI: http://dx.doi.org/10.20337/ISSN2179-3514revistaENTREMEIOSvol13pagina3a14 